\title{
INCLUSION THROUGH THE AGES? Gender, ICT Workplaces, and Life Stage Experiences in England
}

\author{
Marie Griffiths \\ Claire Keogh \\ Karenza Moore \\ Helen J. Richardson \\ Angela Tattersall \\ Information Systems Institute \\ University of Salford \\ Salford, United Kingdom
}

\begin{abstract}
This exploratory paper examines the various challenges that women working in information and communications technology (ICT) in England face in relation to their age, their life stage, and their career stage, with these three aspects being at least partially related. We first examine the literature currently available in relation to women, age and ICT work, arguing that age tends to be the forgotten variable in research on women in ICT. Using eight case studies of individual female ICT professionals in their twenties, thirties, forties, and fifties, we explore the nuances of experience these women have in relation to their career and their caring responsibilities. We consider the possibility that women in ICT may have heterogeneous experiences of working in what are often "masculinized" environments related to, but not determined by, their age. Based on our interpretations of our empirical data, we adapt Super's career-stage theory to better frame our subsequent theoretical assertions. To conclude, we suggest that exploring age, life stage, and/or career stage in relation to female ICT professionals' circumstances and experiences means that we can better theorize gender in the field of information systems, and hence develop more relevant gender inclusion strategies.
\end{abstract}

Please use the following format when citing this chapter:

Griffiths, M., Keogh, C., Moore, K., Richardson, H.J., and Tattersall, A., 2006, in IFIP International Federation for Information Processing, Volume 208, Social Inclusion: Societal and Organizational Implications for Information Systems, eds. Trauth, E., Howcroft, D., Butler, T., Fitzgerald, B., DeGross, J., (Boston: Springer), pp. 153-168. 


\section{GENDER, AGE, AND SOCIAL INCLUSION IN INFORMATION SYSTEMS}

Gender as an issue has largely been excluded from mainstream IS research. In 2004 Adam, Howcroft, and Richardson highlighted a decade of neglect on gender within Information Systems as a discipline, arguing that gender remains under-theorized in IS, while barely featuring as an issue within published literature. ${ }^{\mathrm{I}}$ Efforts to incorporate gender as an issue within the academic IS community have included the establishment of the Gender Research in Information Systems (GRIS) group based at the University of Salford, but such efforts face deeply entrenched views of what practices are, and are not, possible within mainstream IS. As Adam et al. highlight, for example, "some authors-well known in the IS world-save their research on gender for a more feminist audience where they may get a more sympathetic hearing" (p. 235).

While gender is only recently being recognized as an issue within the mainstream IS academic community, 30 years of female underrepresentation in the ICT field in more general terms has received more attention from academics, industry, and government agencies alike. Numerous research projects and centers (such as the UK Resource Centre for Women in Science, Engineering and Technology) exist to tackle the underrepresentation of women in science, engineering, and technology careers, although the figures for women's participation in the ICT sector remain disheartening, with current estimates standing at around 15 percent (EOC 2004). Various innovative initiatives, such as e-Skills' Computer Clubs for Girls, appear to have had little impact on these low female participation rates. Additionally, these and other initiatives have been interpreted as a means to fill the skills gap and "make up the numbers" to boost the UK economy (French and Richardson 2005), resulting in "add more women and stir" solutions to the "problem" of gender in relation to inclusion in IS and ICT (Henwood 1996).

In this context of the neglect of gender issues in mainstream IS, and the continuation of female underrepresentation in the UK ICT sector more generally, it is perhaps unsurprising that IS academics and researchers are reluctant to shift their focus from the ever-important issue of gender to multiple identity affiliations and differences (Cerulo 1997), where gender is one among many considerations. Hence one of the difficulties faced by those working on gender and IS is incorporating possible nuances of gendered experiences according to other identity distinctions including age, class, economic status, ethnicity, disability, sexual orientation, marital status, and geographical location. To offer an example, the interweaving of gender, class, age and nationality have been highlighted in cross-cultural research as important factors in the unfolding of working life biographies (Tulloch and Lupton 2003) and particularly in workers' experiences of labor market insecurity and risk (Mythen 2005). Clearly it is not possible or even desirable to bring in all such concerns when looking at female ICT profes-

\footnotetext{
${ }^{1}$ In an analysis of research papers over a 10 year period (1992-2002) in 10 key IS journals, only 15 papers and one special issue on gender and IS were found. Nine of these papers were quantitative in nature, and Adam et al. (2004) criticize much of this quantitative literature for being essentialist in its theorization of gender as a dichotomy against which differences are measured.
} 
sionals' experiences. However, we suggest that by looking at gender in relation to one or two other identity differences, one may develop a sense in which women's experiences of ICT workplaces are far from homogenous, and in turn answer the call by Adam et al. for a better theorization of gender issues in Information Systems.

In our considerations of female ICT professionals' experiences, we incorporate gender and chronological age with career-stage and life-stage in our analyses of our research participants' circumstances and experiences of working in ICT. Key career stage theorists include Super $(1957,1963,1980)$, who developed the "career-stage theory," and Levinson (1978), who developed the "life-span model." Both have fostered a plethora of work on the effects of career stage and age on an individual's performance and job attitudes. Both have also prompted a wide-range of criticisms ranging from the static nature of each "stage" of the models, to criticisms surrounding the dominance of male subjects in studies testing the viability of each model (Smart 1998). It is now generally recognized that modern careers are more fluid and dynamic than allowed for by older models (Hall 1996; Schein 1996). In addition, Adamson et al. (1998) have noted that the concept of a career itself, as encompassing notions of hierarchical progression, has long been undermined by widespread organizational and economic restructuring in Western societies (p. 251).

Most importantly for our purposes, women may progress through careers at different rates and in varied sequences depending on a variety of factors, often unique to women given wider gender relations, such as expectations on women to be the primary care giver. For this very reason, it may be more helpful to use a stage theory that is at least partially independent of age rather than using solely age-based theories. Age-based retirement stages, for example, are premised on the "ideal type" male retiring following a life-long career, while a woman may "retire" from the workforce to carry out caring responsibilities at a variety of stages in her career. It is in this sense that a woman's life stage (e.g., caring responsibilities) may intermesh with her age and career stage to produce a complex and nuanced set of circumstances and experiences that need differentiated strategies to ensure social inclusion throughout her whole life span.

In order to capture these nuances of the relationship between age, life stage, and career stage, we have adapted and developed the aforementioned career-stage work of Super. Super documented what he saw as four linear career-stages, namely exploration, establishment, maintenance, and decline. In our analysis, we have retained these four stages, but renamed them exploring, establishing, maintaining/reflecting, and restricted freedom. Adapting and developing Super's model, and undermining the linearity of it by highlighting the fluidity of contemporary career trajectories, has meant we are in a position to better reflect women's heterogeneous circumstances and experiences of the ICT labor market in England.

\section{TALKING TO AND LEARNING FROM FEMALE ICT PROFESSIONALS}

The empirical material used in this paper is drawn from data generated by on-going research projects, Women in Information Technology (WINIT), funded by the European Social Fund (ESF), and a recently completed research project Women in North West 
Information Technology (WINWIT), also funded by the ESF. ${ }^{2}$ The research was primarily focused upon women in the ICT industry, or working in ICT in non-ICT organizations, in England and the Northwest of England. ${ }^{3}$ The issue of defining the $\mathrm{ICT}^{4}$ sector is an ongoing complexity within the Information Systems community. Duerden Comeau's (2003) work on defining ICT was used in constructing the research rationale for both the WINIT and WINWIT projects. In framing gender within the ICT sector, the research teams make the assumption that the skills and expertise required from the industry are multidisciplinary and that the work force is generated from within a diverse boundary of disciplines (Cukier et al. 2002).

Drawing on a self-selecting sample of eight female ICT professionals, ${ }^{5}$ the stories we present reflect a broad spectrum of career backgrounds, unique family units, and life experiences, with each woman a pioneer in her own right (Czarnaiwska 2005). Such an approach builds on a long tradition of feminist research that aims to take women's stories and accounts of their gendered experiences seriously, using predominately qualitative and ethnographic methods to explore their thoughts and actions (McRobbie 1997).

Our narrative approach falls within a critical research framework with emancipatory ideals of listening to "silenced voices" (Bowen and Blackmon 2003), giving voice to marginalized groups (Cecez-Kecmanovic 2005), and letting stories be heard (Richardson and Howcroft 2006). The process of conducting critical research means disrupting ongoing social reality to question what is ignored or taken for granted and to tell those stories often left untold (Alvesson and Deetz 2000). By attempting to hear silenced and multiple voices and stories through narrative techniques, we can pay better attention to the diversity of women's lives and experiences (Spraque and Kobrynowicz 2004, p. 91) and explore the social experiences of silenced groups (Oakley 1981, p. 89).

The narrative approach we used in our research was chosen in part for its sensitivity to heterogeneity within and across collective experiences, and in part for its sensitivity to the coproduction of knowledge between researcher and the participant. Feminist and critical research positions acknowledge the place of the researcher in producing knowledge, primarily through reflexive thinking (Oakley 2000). Reflexivity is a tool where a researcher recognizes, examines, and tries to understand how her social background, positionality, and assumptions shape the practice of research (Hesse-Biber and Yaiser 2004 , p. 115), making this shaping as visible as possible to participants. In research

${ }^{2}$ For information on WINIT and WINWIT, please see their websites at http://www.isi.salford.ac.uk/gris/winit and http://www.isi.salford.ac.uk/gris/winit, respectively.

${ }^{3}$ Although many of the women interviewed work in global ICT corporations, the research is inevitably positioned in the context of the English labor market.

${ }^{4}$ The broad convergence of communications with information technology has led to a recent shift of these industries being classified as ICT. For a detailed discussion of the difficulties of defining IT, ICT, and the ICT industry, see Duerden Comeau (2003).

${ }^{5}$ The women included in this study answered a general call for research participants made by the WINIT team through a wide variety of channels. The eight stories in this paper comprise of narrations selected from a series of informal (semi-structured) interviews conducted between March and September 2004. Each interview lasted 90 minutes, and was held either in the participant's office or a mutually convenient venue. Interviews were recorded and transcribed. 
terms this meant writing ourselves into the research (Piacentini 2005, p. 204), for example, by telling stories of our own experiences of working in ICT during the interview process and encouraging participants to do the same.

We now construct short summaries of the circumstances and experiences of eight women who were interviewed for the WINIT/WINWIT projects. Each woman has been paired with a woman in the same age range (i.e., twenties, thirties, forties, and fifties) so that we may better compare and contrast their experiences. We suggest that by using in-depth, qualitative material such as interviews to draw out similarities and contradictions apparent between and across women's accounts, we may find ways in which gender can be explored in relation to other issues such as age, career stage, and life stage, while preserving the heterogeneity of experiences which we feel is vital to incorporate in work on social inclusion/exclusion.

\section{INCLUSION AND EXCLUSION THROUGH THE AGES AND CAREER-STAGES}

\subsection{Exploring? Female ICT Professionals in Their Twenties}

\subsubsection{Beatrice's Story ${ }^{6}$}

Neither university educated, nor technically qualified, Beatrice, 26 years of age, owns a computer reselling and distribution business with her partner. Her driving ambition is "a massive house and a flash car." Perceiving that in the past she had "disappointed her father," her other source of motivation includes "determination to succeed and try to prove to him wrong." Beatrice's ICT sales career started at 17 years of age, having being told "to get into IT because you will earn loads of money." She established herself as the "youngest product manager" with the "highest wage" at 19 in South-East England. Circumstances, including an offer of higher wages, induced a move to Northern England to a company where again she was the "only girl who worked there apart from the receptionist." In career-terms, she thrived in this environment, saying, "they hated me and I pulled all their big accounts." She was subsequently sacked just before she was meant to collect $£ 100,000$ commission. This proved a turning-point in Beatrice's career trajectory. In an example of her determined attitude, she says, "I said what better opportunity have we got" and consequently she started her own business with her long-term partner. Two-years later, their reselling and distribution business is an award winning success story. In addition, she recently set up a woman's ICT training forum. Beatrice works seven days a week. In relation to starting a family, she says, " $I$ would love to have kids and then I think I'd have to have a day off."

${ }^{6} \mathrm{Names}$ have been changed to ensure anonymity. 


\subsubsection{Gayle's Story}

Highly qualified, Gayle, a 27-year old business consultant in London, has rapidly climbed the ICT career ladder. Working for a global organisation in a predominantly male environment, she is "much more visible. I am remembered a lot more." Essential networking and negotiation skills have also contributed to ensuring her selection in an aggressive internal recruitment market. She is ambitious, has high expectations of herself and her career, and works hard. This combination has enabled her progression from junior software developer to general management status over a 6-year period. Gayle's current role requires longer periods away from home. Extra responsibilities have brought added pressure to Gayle's life, and some uncertainty about the future, "I have no idea where it will go. I will either get used to it...some days I think why am I doing this." Involvement in the company's "ridiculously long-hours" culture of 12-hour days and attending evening team meetings leaves Gayle little time for life beyond work; "I barely have time to look after myself." Secure in a relationship, her partner is in a similar IS role but in the public sector. Gayle says, with regard to having a family in the future, that "I honestly can't see how I'd do it [the job] with children and spend any time with them." In the meantime Gayle is happy to spend some of her earnings on her passion: exotic scuba-diving holidays.

\subsubsection{Exploratory? Discussion of Women in Their Twenties}

From polar opposite starts, these two women have continuously worked hard since their school days. Beatrice left school "a failure" without any qualifications or family support, taking only confidence and the determination to succeed and a relentless ambition to make money. Gayle, educated at a selective, independent girls' school, left with five A-levels and a determination to succeed. These alternative groundings have guided these women's approach to their chosen career trajectories and help us understand these women's motivations for working extremely hard, long-hours, leaving them little time for their personal lives. Only 26, Beatrice has had a dynamic 8-year career in the ICT industry, changing roles, changing organizations, and relocating without hesitation. Similarly Gayle, while moving in a relatively linear manner along her chosen career path, has undertaken a number of diverse roles, leading her to specialize in document management and procure a managerial position. Both women have explored the various opportunities available to them in ICT, and are moving into positions in which they can become more established in their careers.

This exploratory stage finds Beatrice working 7 days a week. In comparison, Gayle took a more traditional, university-based route, starting on a graduate training scheme in global ICT consultancy that experienced three mergers within a 6 year period. Staying in one company has enabled Gayle to explore a broad spectrum of project work. These women are not currently prioritizing work-life balance but instead are working hard to achieve job status and related financial rewards. While both women have longterm partners and no dependants, and so in a sense are working without family constraints, they are aware that they may be unable to continue this pace of work if they wish to have a family. When both women contemplated how children would impact 
upon their current lifestyles, they looked around for female role models, of which there is a scarcity and a need (Faulkner 2004, p. 13). Gayle says, for example, "People in my position don't have kids, or they are older men with wives at home." The most recent report by the Department of Trade and Industry on women in the IT industry also addresses this issue, highlighting an "anti-women culture" in many IT organizations that results in a "loss of opportunities when women are of childbearing age" (DTI 2005, p. 19). Here we see how gender, age, career-stage, family choices, work-life balance priorities, the male-domination of ICT workplaces, and wider factors such as the societal expectation for women to be the main care-givers in a family, all combine to shape the ways women at the early stages of their ICT careers.

\subsection{Establishing? Female ICT Professionals in Their Thirties}

\subsubsection{Mary's Story}

Mary is a 34-year-old mother of two young children who entered the ICT labor market in an ICT support role. With no formal ICT qualifications, she progressed to the position of Technical Trainer for Europe for a global ICT organization before being made redundant. During her career she often worked long hours, and was extremely career focused and ambitious. She states she has no maternal feelings for her children, "I am not a mother by any stretch of the imagination, I can't be a mother." She feels frustrated for not networking and socializing more while employed, saying, "If I socialized a lot more, I would know a lot more people and I could use that knowledge to network to get back into the industry." She suspects her previous lack of networking has affected her current ability to find employment. Mary found being made redundant difficult given her previous frantic workload. She says, "Being in the industry for 13 years and working 60 hours a week, I sat on the sofa not knowing what to do with myself...I literally went through death." She is eager to return to ICT.

\subsubsection{Jasmine's Story}

Jasmine is a woman in her thirties who works for a large private organization as a Service Delivery Manager. She is currently single and has no children or care giving responsibilities. After gaining a degree in European Studies, Jasmine entered the ICT labor market by chance in June 2000 as a "temp." A permanent position, a two-year secondment to London, and a promotion, quickly followed. However, she indicates that she does not want to progress to a more senior management position within her organization - "I don't personally have massive career aspirations anymore"-after experiencing a number of difficult challenges during her career. She had a particularly incompetent and malevolent senior manager who bullied her, and was working exceptionally long hours away from family and friends. She subsequently became ill and had to take considerable sick leave due to stress. On returning to work with renewed vigor 
and reevaluating her career options, Jasmine feels she is now more aware of her worklife balance needs. Working in the private sector for a profit-focused organization and gaining a high salary and other financial benefits no longer solely motivates Jasmine. She expressed how she would gladly exchange the cut-throat and long hour's culture of private ICT companies for a position in the public sector, where she believes the stress is reduced.

\subsubsection{Establishing? Discussion of Women in Their Thirties}

While it may be expected, according to a linear career stage, that women in their thirties would be well established in their career, wider economic and social forces that shape the ICT labor market means the context for such women's careers may change due to redundancy and/or downsizing, outsourcing, geosourcing, and so on. As Mary's story highlights, a sometimes drastic change in circumstances may occur at any point of the career stage, meaning that female ICT professionals of various ages may have to reorientate themselves in relation to their personal and work-centered trajectories. To continue this theme of disruption to a linear career-stage model, the bullying Jasmine was subjected to in her current workplace meant for her a reevaluation of what was formerly a reasonably well-established career. The ICT sector's long-hours culture, higher job demands, "chilly" workplace culture (Faulkner 2004), and lack of work-life balance initiatives (DTI 2004) have contributed to high levels of stress, particularly for Jasmine-contributing to her weakened emotional well-being and increased absence due to illness (Bond 2004). Although Jasmine does not have a partner or children, she is now in her thirties with increased financial responsibilities (such as a mortgage). Hence, she may be less likely to take risks by changing firms, being less mobile at this point in her life stage than those women in their twenties (or those at different life stages) who focus on employability rather than job security (Finegold et al. 2002).

Traditionally, career-ambitious women are often measured against the male norm and successful individuals are described as ruthless with continuous dedication to a career goal rewarded with high salary, progression, and prestige (O'Leary 1997). Although well established in her career this trajectory has been rejected by Jasmine. In comparison, while some may portray non-maternal women as "unnatural" (Christ 2004), Mary is highly ambitious and chose to reject caring responsibilities in favor of career focus. However, reentry to the ICT industry after redundancy has proved problematic, since leaving a senior post without a web of social relations, information and support has limited Mary's reemployment opportunities (Tharenou 1999). In short, both Mary and Jasmine have had to work at reestablishing their careers, a situation that links in with the vagaries of the ICT labor market, and their particular experiences of the masculinized domain $^{7}$ of many ICT workplaces (Griffiths and Moore 2006).

${ }^{7}$ The notion of masculinized domain suggests that, within certain spheres of social life, such as ICT workplaces, men tend to dominate proportionately and symbolically. 


\subsection{Maintaining/Reflecting: Female ICT Professionals in Their Forties}

\subsubsection{Janine's Story}

Janine is in her forties and a mother of two. She is employed by a global ICT organization as Partner, Industry Leader for Computer Systems Integrator Europe, Middle East, and Africa. She moved into ICT via a background in sales where she thrived on achieving and exceeding targets. Janine perceives that her lack of assertiveness in her early career meant she was not offered the same promotion opportunities as her male colleagues. She feels she has worked so hard for the organization that she did not put enough effort into her personal and professional development. She maintains that being based in the North-West of England has been restrictive in career terms, saying, "I think I would have got to where I am now a good few years earlier had I been more able to liaise and socialize with senior male executives, whereas 200 miles away I am out of sight out of mind." She has found managing her career and children problematic. When the children were young, Janine employed a nanny to provide childcare, enabling her to maintain a career focus. She demonstrates some regret with this decision, saying, "Sometimes I used to think they loved her more than me." Janine remains ambitious and is seeking further promotion. However, she is conscious about making the right decision for herself and her family. She concludes, "I don't want to get divorced and my children become strangers to me."

\subsubsection{Habibah's Story}

Currently Director of ICT and planning to undertake an MBA, Habibah's ICT career began when she became a single mother of three children at the age of 30 . Exploring the options available to her, she decided on a career in ICT, gaining 38 qualifications in 5 years while she worked in administrative roles. Strategically not applying for ICT roles until highly qualified, Habibah's career began in earnest with the offer of Head of ICT as her first ICT post. She recounts how she "went home and cried and cried because I thought, my God, I am never going to be able to do this." Her hectic professional life is coupled with an equally eventful domestic life, with a family of five ranging from an 18-year-old to a new-born child. She is supported by an extended family. She admits that 23 hour days are not unusual, and that she has not "quite got the balance right between my family and my career because my career seems to take precedence at the moment." Habibah is currently reflecting on her past experiences and making plans for the future. She aims to publish a technical book, but also wishes to move toward a situation whereby "work is centered around the family, because I feel I have neglected the family and they have paid the price." This dynamic, driven, and honest woman admits that she has not managed to achieve a work-family balance However, now ; that her professional reputation is established, she feels she is better able to contemplate the future of her family, aiming to "be there, especially for the younger ones." 


\subsubsection{Maintaining/Reflecting? Discussion of Women in Their Forties}

Borrowing Howcroft and Wilson's (2003) metaphorical use of the two-headed Janus $^{8}$ of the IS/ICT professional who is forced to look two ways (i.e., work and family) enables the exploration of the nuances of the female IS/ICT professionals who are also a parents. Clearly, not all female IS/ICT professionals are parents. However, many are, and such caring responsibilities at diverse stages of a woman's career may have a differential impact upon a her work-life balance, and hence the kinds of inclusion strategies needed. Both Janine and Habibah highlighted the ways in which their careers have taken precedent over the family at various points in their life-stage, a trade-off emphasized by Liff and Ward (2001) in their work on female senior managers. The women in our forties age group have job status, career ambition, and high aspirations "to move onward and upward," as Janine says. Women in their forties, and those women at the maintaining/reflecting stage of their careers, are often maintaining their job status, but also reflecting on their past, present, and possible future experiences (Moore and Griffiths 2005). Work pressures, a "presenteeism" culture within contemporary workplaces (Simpson 1998) and lifestyle preferences predisposed both women to take minimum maternity leave. As Janine says, "I went back when she was three months old." The juxtaposition of work-family conflict is a bidirectional construct (Posig and Kickul 2004) because these women "want to be there for my kids and husband" but are also steadfastly focused upon the next career move. The maintaining/ reflecting career stage, for women of any age, is one in which family responsibilities, career choices and pressures, and lifestyle preferences combine to present women with a very particular, and highly gendered, set of conflicts.

\subsection{Restricted Freedom? Female ICT Professionals in Their Fifties}

\subsubsection{Eve's Story}

Eve is a woman in her fifties with a working partner and two adult children. She has recently taken voluntary early retirement. She began her career as a punch card operator before moving into COBOL programming. For 16 years, she was employed as a Business Analyst in the public sector. After being internally head hunted to the post of Business Analyst, Eve became disheartened and bored - a situation that reached deadlock when very little new work and few new challenges were presented to her. During her time in the public sector, Eve received no training to update her skills and felt she was not qualified to apply for posts elsewhere. She regrets staying with the same em-

\footnotetext{
${ }^{8}$ Janus was the Roman god of gates and doorways, depicted with two faces looking in opposite directions.

${ }^{9}$ Presenteeism can be defined as the social/peer pressure to be seen to be at work beyond the call of duty and beyond contract stipulations, possibly to improve promotion prospects.
} 
ployer for such a long period of time. She feels this has hindered her pay and promotion opportunities. She recommends, based on her experiences, "changing your employer more often, don't stay at the same place because that's how you get your promotions." Eve is concentrating on a new career as a horse trainer, her hobby of many years.

\subsubsection{Jayne's Story}

Jayne is an award winning 57-year-old ICT professional who has reached the peak of her career. She sits on the board of a global legal firm in addition to her entrepreneurial role in management consultancy. A serendipitous career trajectory began in the 1960s as personal assistant to a deputy chairman of one of the UK's largest insurance organizations. She says of her current position, "If you walk into any firm of [solicitors] and say who do you know in legal technology, I would be stumned if my name is not in the first three." Jayne's management of process and procedures to "analyze the way people worked" created a relationship with IBM where she worked on developing industry specific technology. She recounts how she "used to go and lecture for IBM all over the world." A high profile women's networking forum has also been added to Jayne's busy schedule. Her hectic career of long hours, hard work and determination witnesses Jayne getting "up at 4:50 a.m. to catch the 6:03 a.m.... so I hit my desk at 7:10 a.m." Working 12 hours days, she also "keeps on top of e-mails of a weekend." She is happily married but says, "we didn't have kids so I don't have to make the trade off." She has caring responsibilities for her sick, elderly parents, although her partner appears to shoulder the bulk of the daily care work involved.

\subsubsection{Freedom? Discussion of Women in Their Fifties}

The UK labor force in general is being subjected to a profound demographic shift as proportionally the population aged 50 and over is beginning to surpass younger age groups (Platman and Taylor 2004). In accordance to the linear career-stage, these women in their fifties are experiencing a certain amount of freedom and/or restricted freedom. They are free in the sense that they do not have children at home to look after, and free in the sense that they can shape the ways in which they use their time, albeit in very different ways. Eve is pursuing her long-term hobby and moving away from IS/ ICT work. Conversely, Jayne is continuing to pursue a very successful career, while diversifying into management consultancy and the design and production of women's forums.

Despite this greater freedom in later career-stages, many women still hold the majority of the responsibility for home, family, and children (Gordon and Whelan-Berry 2004). Eve's interruption to a linear career-stage model and subsequent early departure from the ICT labor market is partly due to her individual characteristics (lack of promotion) and organizational-related factors (lack of training opportunities), leading to her lack of career satisfaction (Armstrong-Stassen and Cameron 2005). It appears that for many years Eve has been "psychologically retired" (O'Neil and Bilimoria 2005). Given her longevity at one organization, she was able to plan and negotiate her transition into retirement. Conversely, Jayne's career has been innovative, exciting, and rewarding. 
In contrast to Eve, and in a twist to Super's (1957) fourth and final career-stage, decline, Jayne is resisting withdrawing from the work-force. While Jayne's freedom is restricted somewhat in that she has elder care responsibilities, this is presently being undertaken by her spouse. Equally, while Eve has greater freedom by instigating a late life career change, she still has restrictions due to caring responsibilities for her adult children, practically, emotionally and financially. The career stage both women have reached means that they are now in the position, and have the freedom and/or restricted freedom, to reconceptualize, pursue, and achieve new opportunities and challenges ( $\mathrm{O}$ 'Neil and Bilimoria 2005).

\section{CONCLUSIONS}

Given our concern with gender, age, career-stage, and life-stage, we have adapted Super's career-stage model to help us draw out some of the key themes identified in interviews with our female research participants. Super identifies the key career-stages as follows: exploration, establishment, maintenance, and decline. We have retained Super's four stages, but renamed them exploring, establishing, maintaining/reflecting, and restricted freedom, to better reflect women's circumstances and experiences in the ICT labor market, and the fluidity of contemporary career trajectories. We use age as a key difference marker among our sample of women in order to build coherence into our model at this preliminary stage of our research. However, in keeping with our nondeterministic approach, we maintain that women of different ages may move between, or across, these different stages at various points in their lives. A female professional in her thirties, for example, may feel moved to reflect on her career choice and decide to leave the ICT industry if she has an unpleasant experience during the establishing stage of her career, as was the case with Jasmine.

We suggest that one of our key contributions to the theorization of gender in IS is highlighting the heterogeneity in experiences based on collective rather than individual identity distinctions, such as age, class, socio-economic status, and ethnicity. We adapted Super's career-stage model to better theorize lived experiential heterogeneity as coalescing around age and career stage and life stage, these being specific cultural, structural, and relational identity markers of difference. As Cerulo (1997) notes, "The existence of these multiple categories alerts us to the flaws of binary gender conceptualizations, focusing us instead on the ways in which multiple identity affiliations qualitatively change the nature of human experience" (p. 392).

We acknowledge the limitations of our empirical research and our preliminary theoretical model. The main shortcoming is that our empirical data was gathered from female ICT professionals in England, and hence the generalizability of our findings to other countries needs to be investigated through further research. The possibility remains that our theoretical assertions may be limited to the particularities of English society, although equally there is the possibility that our model is appropriate, perhaps following culturally specific adaptation, to female ICT professionals' experiences in other Western societies and beyond.

To conclude, we argue that when developing strategies for social inclusion in the fields of information systems and information communication technologies (see 
Faulkner 2004), we need to consider the experiences of women based on their age, their career stage, and any family and domestic responsibilities they may have depending on their life-stage. We suggest that when devising strategies for social inclusion that focus on gender, an awareness of the heterogeneity of female ICT professionals' experiences according to other concerns such as those highlighted in this paper may lead to more robust and positive outcomes. One of our key concerns is that age, and indeed gender, is not taken as an inflexible, deterministic variable, but instead can be used as a sensitizing difference marker in conjunction with concepts such as career stage and life stage. This helps to explore the possibility of a diversification of responses to the continuation of female underrepresentation in the UK ICT sector which remains an important area of research.

\section{References}

Adam, A., Richardson, H., and Howcroft, D. "A Decade of Neglect: Reflecting on Gender and IS," New Technology, Work and Employment (19:3), 2004, pp. 222-241.

Adamson, S. J., Doherty, N., and Viney, C. "The Meanings of Career Revisited: Implications for Theory and Practice," British Journal of Management (9:4), 1998, pp. $251-259$.

Alvesson, M., and Deetz, S. Doing Critical Management Research, London: Sage Publications, 2000.

Armstrong-Stassen, M., and Cameron, S. "Factors Related to the Career Satisfaction of Older Managerial and Professional Women," Career Development International (10:3), May 2005, pp. 203-215.

Bond, S. "Organizational Culture and Work-Life Conflict in the UK," International Journal of Sociology and Social Policy (24:12), December 2004, pp. 1-24.

Bowen, F., and Blackmon, K. "Spirals of Silence: The Dynamic Effects of Diversity on Organizational Voice," Journal of management Studies $(40: 6), 2003$, pp. 1391-1417.

Cecez-Kecmanovic, D. "Basic Assumptions of the Critical Research Perspective in Information Systems," in D. Howcroft and E. M. Trauth (eds.), Handbook of Critical Information Systems Research Theory and Application, Cheltenham, UK: Edward Elgar, 2005.

Cerulo, K. "Identity Construction: New Issues, New Directions," Annual Review of Sociology (23), 1997, pp. 385-409.

Christ, C. "Inside the Clockwork of Women's Careers," speech to the European Professional Women's Network, Paris, September 21, 2004.

Cukier, W., Shortt, D., and Devine, I. "Gender and Information Technology: Implications of Definitions," SICGSE Bulletin (34:4), 2002, pp. 142-148.

Czarnaiwska, B. "The Thin End of the Wedge," keynote speech presented at the at Gender, Work and Organization Conference, University of Keele, UK, June 22-24, 2005.

Duerden Comeau, T. "Information Technology (IT) Employment: What is IT?," working paper, Workforce Ageing in the New Economy (WANE), University of Western Ontario, 2003 (available online at http://www.wane.ca/PDF/WP1.pdf). 
DTI. "Flexible Working in the IT Industry: Long-Hours Cultures and Work Life Balance at the Margins?," report to the Department of Trade and Industry and the Women and IT Forum, March 2004 (http://www.dti.gov.uk/).

DTI. "Women in the IT Industry: Phase 2 Research: How to Retain Women in the IT Industry," Department of Trade and Industry, 2005 (http://www.dti.gov.uk/).

EOC. "Plugging Britain's Skills Gap: Challenging Gender Segregation in Training and Work," report of Equal Opportunities Commission, Manchester, UK, May 2004 (available online from http://www.eoc.org.uk/pdf/phaseone.pdf).

Faulkner, W. "Strategies of Inclusion: Gender and the Information Society," University of Edinburgh/European Commission IST Programme, August 2004 (available online at www.rcss.ed.ac.uk/sigis/public/documents/SIGIS_D08_Final_Public.pdf).

Finegold, D., Mohrman, S., and Spreitzer, G. "Age Effects on the Predictors of Technical Workers' Commitment and Willingness to Turnover," Journal of Organizational Behavior (23), February 2002, pp. 655-674.

French, S., and Richardson, H. "Opting Out? Women and On-Line Learning," Computers and Society (35:2), June 2005 (available online at http://doi.acm.org/ 10.1145/1111646.1111648).

Gordon, J. R., and Whelan-Berry, K. S. "It Takes Two to Tango: An Empirical Study of Perceived Spousal/Partner Support for Working Women," Women in Management Review (19:5), 2004, pp. 260-273.

Griffiths, M., and Moore, K. "Issues Raised by the WINIT Project," in E. M. Trauth (ed.), Encyclopedia of Gender and Information Technology, Hershey, PA: Idea Group Inc., 2006 (forthcoming).

Hall, D. T. The Career Is Dead, Long Live the Career, San Francisco: Jossey-Bass Publishers, 1996.

Henwood, F. "WISE Choices? Understanding Occupational Decision-Making in a Climate of Equal Opportunities for Women in Science and Engineering," Gender and Education (8:2), 1996, pp. 199-214.

Hesse-Biber, S. N., and Yaiser, M. L. "Difference matters: Studying Across Race, Class, Gender and Sexuality," in S. N. Hesse-Biber and M. L. Yaiser (eds.), Feminist Perspectives on Social Research, Oxford, UK: Oxford University Press, 2004, pp. 101-120.

Howcroft, D., and Wilson, M. "Paradoxes of Participatory Practices: The Janus Role of the Systems Developer," Information and Organization (13:1), 2003, pp. 1-24.

Levinson, D. The Seasons of a Man's Life, New York: Knopf, 1978.

Liff, S., and Ward, K. "Distorted Views through the Glass Ceiling: The Construction of Women's 'Understandings of Promotions and Senior Management Positions," Gender Work and Organizations (8:1), 2001, pp. 19-36.

Moore, K., and Griffiths, M. "Gendered Futures? Women, the ICT Workplace, and Stories of the Future," in Book of Abstracts, $4^{\text {th }}$ Interdisciplinary Conference, Keele University, Staffordshire, UK, June 22-24, 2005.

McRobbie, A. "The E's and the Anti-E's: New Questions for Feminism and Cultural Studies," in M. Fergusson and P. Golding (eds.), Cultural Studies in Question, London: Sage Publications, 1997, pp. 170-186.

Mythen, G. "Employment, Individualization and Insecurity: Rethinking the Risk Society Perspective," The Sociological Review (53:1), 2005, pp. 129-149. 
Oakley, A. Experiments in Knowing: Gender and Method in the Social Sciences, Cambridge, UK: Polity Press, 2000.

Oakley, A. Subject Women, Oxford, UK: Martin Robinson, 1981.

O'Leary, J. "Developing a New Mindset: The Career Ambitious Individual," Women in Management Review (12:3), 1997, pp. 91-99.

O'Neil, D., and Bilimoria, D. "Women's Career Development Phases: Idealism, Endurance, and Reinvention," Career Development International (10:3), May 2005, pp. $168-189$.

Piacentini, L. "Cultural Talk and Other Intimate Acquaintances with Russian Prisons," Crime, Media, Culture (1:2), 2005, pp. 189-208.

Platman, K., and Taylor, P. "Workforce Ageing in the New Economy: A Comparative Study of Information Technology Employment," University of Cambridge, 2004. (available online at http://www.circa.cam.ac.uk/index.html).

Posig, M., and Kickul, J. "Work-Role Expectations and Work Family Conflict: Gender Differences in Emotional Exhaustion," Women in Management Review (19:7), 2004, pp. 373-386.

Richardson, H., and Howcroft, D. "The Contradictions of CRM: A Critical Lens on Call Centres," Information and Organization (16:1), Jarnuary 2006, pp. 56-81.

Schein, E. H. "Career Anchors Revisited: Implications for Career Development in the $21^{\text {st }}$ Century," Academy of Management Executive (10:4), 1996, pp. 80-89.

Simpson, R. "Presenteeism, Power and Organizational Change: Long Hours as a Career Barrier and the Impact on the Working Lives of Women Managers," British Journal of Management (9:Special Issue), 1998, pp. 37-50.

Smart, R. M. "Career Stages in Australian Professional Women: A Test of Super's Model," Journal of Vocational Behavior (52), 1998, pp. 379-395.

Sprague, J., and Kobrynowicz, D. "A Feminist Epistemology," in S. N. Hesse-Biber and M. L. Yaiser (eds.), Feminist Perspectives on Social Research, Oxford, UK: Oxford University Press, 2004, pp. 78-98.

Super, D. E. "The Definition and Measurement of Early Career Behaviors: A First Formulation," Personnel and Guidance Journal (41), 1963, pp. 775-779.

Super, D. E. "A Life Span, Life Space Approach to Career Development," Journal of Vocational Behavior (16), 1980, pp. 282-298.

Super, D. E. The Psychology of Careers: An Introduction to Vocational Development, New York: Harper, 1957.

Tharenou, P. "Gender Differences in Advancing to the Top," International Journal of Management Reviews (2), June 1999, pp. 1-22.

Tulloch, J., and Lupton, D. Risk and Everyday Life, London: Sage Publications, 2003.

\section{About the Authors}

Marie Griffiths is currently working on Disappearing Women Project: Northwest ICT, researching why women leave the ICT sector for good! Marie initially joined the IS Department at Salford in 2004 to work on the Women in IT (WINIT) project (2004-2006) and closed that project with an international and interdisciplinary conference on Gender, Technology and the ICT workplace (details of which can be 
found at http://www.winit-salford.com/conference). Marie is due to complete her Ph.D. in the area of organizations, metaphors, and user resistance later this year and she can be contacted at m.griffiths@salford.ac.uk.

Claire Keogh is currently working as a research assistant for the Directing Equal Pay in ICT project Claire graduated with a degree in Information Technology from the University of Salford in 2003. Since graduating, Claire has become a managing director for ARC Business IT Solutions Limited, an organization serving small to medium enterprises in the Northwest. Additionally she is continuing her studies at Salford by exploring the field of gender and information technology. E-mail Claire at c.keogh@salford.ac.uk.

Karenza Moore is currently working on the Disappearing Women Project: Northwest ICT. She joined the IS Department in Salford in 2004 as a research associate on the Women in IT (WINIT) project. Karenza's research interests include gender and IS and future-oriented discourses surrounding new technologies. She also conducts research on clubbing and related recreational drug use in the UK.

Helen J. Richardson is a senior lecturer in Information Systems and joined the University of Salford in 1998 after a varied career including working in the field of social care and running a research and training unit promoting positive action for women at work. She is engaged in critical research in IS including issues of gender in the ICT labor market. Helen can be reached at H.Richardson@salford.ac.uk.

Angela Tattersall is currently working as a research assistant for the Directing Equal Pay in ICT project and undertaking postgraduate study in the area of gender and technology. Angela joined the Information Systems Institute in January 2004 as a research assistant to investigate issues relating to gender and technology. Projects to date include Women In North West IT and the current Directing Equal Pay in ICT. Additionally she was previously employed at Manchester Metropolitan University as a part-time lecturer in the department of Information Communications. E-mail Angela at a.l.tattersall@salford.ac.uk. 